\title{
Diagnosis and follow-up evaluation of central nervous system vasculitis: an evaluation of vessel-wall MRI findings
}

\author{
Maximilian Patzig ${ }^{1}$ (D) Robert Forbrig ${ }^{1} \cdot$ Clemens Küpper $^{2} \cdot$ Ozan Eren $^{2} \cdot$ Tobias Saam $^{3,4} \cdot$ Lars Kellert $^{2}$. \\ Thomas Liebig ${ }^{1} \cdot$ Florian Schöberl $^{2}$
}

Received: 21 February 2021 / Revised: 19 June 2021 / Accepted: 21 June 2021 / Published online: 8 July 2021

(c) The Author(s) 2021

\begin{abstract}
Objective To approach the clinical value of MRI with vessel wall imaging (VWI) in patients with central nervous system vasculitis (CNSV), we analyzed patterns of VWI findings both at the time of initial presentation and during follow-up.

Methods Stenoocclusive lesions, vessel-wall contrast enhancement (VW-CE) and diffusion-restricted lesions were analyzed in patients with a diagnosis of CNSV. On available VWI follow-up, progression, regression or stability of VW-CE were evaluated and correlated with the clinical status.

Results Of the 45 patients included, 28 exhibited stenoses visible on MR angiography (MRA-positive) while 17 had no stenosis (MRA-negative). VW-CE was found in 2/17 MRA-negative and all MRA-positive patients $(p<0.05) .79 .1 \%(53 / 67)$ of stenoses showed VW-CE. VW-CE was concentric in $88.3 \%$ and eccentric in $11.7 \%$ of cases. Diffusion-restricted lesions were found more frequently in relation to stenoses with VW-CE than without VW-CE $(p<0.05) .48 \mathrm{VW}-\mathrm{CE}$ lesions in 23 patients were followed over a median time of 239.5 days. $13 \mathrm{VW}-\mathrm{CE}$ lesions (27.1\%) resolved completely, 14 (29.2\%) showed partial regression, 17 (35.4\%) remained stable and 4 (8.3\%) progressed. 22/23 patients received immunosuppressive therapy for the duration of follow-up. Patients with stable or progressive VW-CE were more likely $(p<0.05)$ to have a relapse $(14 / 30$ cases) than patients with partial or complete regression of VW-CE (5/25 cases).

Conclusion Concentric VW-CE is a common finding in medium/large-sized vessel CNSV. VW-CE might represent active inflammation in certain situations. However, follow-up VWI findings proved ambiguous as persisting VW-CE despite immunosuppressive therapy and clinical remission was a frequent finding.
\end{abstract}

Keywords Cerebral vasculitis $\cdot$ Stroke $\cdot$ Vessel wall imaging $\cdot$ MRI $\cdot$ Follow-up

\section{Introduction}

Central nervous system (CNS) vasculitis is a rare disease characterized by different etiologies, heterogeneous findings and a lack of definite diagnostic markers. Thus it poses great challenges regarding both diagnosis and treatment [1-6].

Maximilian Patzig

maximilian.patzig@med.uni-muenchen.de

1 Insitute of Diagnostic and Interventional Neuroradiology, Ludwig-Maximilians-University Munich, Munich, Germany

2 Department of Neurology, Ludwig-Maximilians-University Munich, Munich, Germany

3 Institute of Clinical Radiology, Ludwig-Maximilians-University Munich, Munich, Germany

4 Radiological Center Rosenheim, Rosenheim, Germany
Since therapy usually consists of long-term immunosuppression with potential major adverse effects [5, 6], it is essential to establish a definite diagnosis and to evaluate the treatment response carefully. Along with clinical and laboratory findings, imaging is crucial in the work-up of CNS vasculitis [7]. However, findings of both digital subtraction angiography (DSA) and conventional magnetic resonance imaging (MRI) including magnetic resonance angiography (MRA) are unspecific regarding CNS vasculitis [8-10]. While evidence of systemic vasculitis or CNS infection can help establish the diagnosis of CNS vasculitis in some cases, brain biopsy is considered mandatory to prove primary angiitis of the central nervous system (PACNS) [5, 7, 11, 12]. Yet even biopsy has a limited sensitivity with a relevant rate of false negative results, particularly when only medium- and/ or large-sized vessels are affected [13-17]. 
Therefore, advances regarding diagnostic tests for CNS vasculitis are required. MRI with dedicated vessel wall imaging has been proposed in this respect [18-20]. Vessel wall imaging uses different techniques to suppress the signal of intraluminal blood ("black blood imaging"), thus allowing evaluation of the vessel wall and possibly the detection of inflammatory changes within the vessel wall [19, 21]. Vessel wall contrast enhancement has been reported as a potential sign of CNS vasculitis as early as 2008 [22]. Vessel wall contrast enhancement in patients with CNS vasculitis is presumed to be caused by hyperpermeability of the endothelium and/or by neovascularization, resulting in leakage of contrast into the arterial wall either from the lumen of the main vessel or from vasa vasorum [19]. Vessel wall imaging is now used in suspected CNS vasculitis in many neurovascular centers [19]. However, there is still an eminent lack of original research on this subject, which is certainly due to the rarity of the disease. To date, there are only a few case reports and series evaluating vessel wall imaging in CNS vasculitis, with 29 patients being the largest reported CNS vasculitis group to our knowledge [23]. Even less data is available concerning follow-up MRI with vessel wall imaging in CNS vasculitis patients. According to our literature research, the largest study groups in which followup vessel wall imaging results were specifically reported comprise only six patients $[24,25]$. Thus the role of vessel wall imaging both regarding the diagnosis of CNS vasculitis and monitoring disease activity, particularly in response to immunosuppression, remains largely unproven.

It is for these reasons that we retrospectively evaluated clinical and radiological data of patients with CNS vasculitis treated at our institution, aiming to contribute data on the pattern of vessel wall imaging findings both at the time of initial presentation and at follow-up.

\section{Methods}

\section{Patients}

We searched the electronic medical records of the Department of Neurology of our institution from September 2008 to December 2019 for adult patients ( $\geq 18$ years) with suspected CNS vasculitis. The time span was chosen because dedicated vessel wall MRI has been used at our institution since September 2008.

In a second step, the diagnoses of CNS vasculitis were reviewed. For the purpose of this study, CNS vasculitis was defined as an inflammatory vasculopathy of cerebral arteries, either restricted to the CNS or as part of a systemic disease. The latter included CNS-manifestations of systemic autoimmune mediated vasculitis (for a systematic classification see Table 1) and vasculitic changes associated with viral
Table 1 Classification of systemic vasculitides (adapted from the guidelines for CNS vasculitis of the German Neurological Society [27] and the Chapel Hill Consensus Conference Nomenclature [28])

\begin{tabular}{|c|c|}
\hline Affected vessel type & Type of vasculitis \\
\hline Large vessels & $\begin{array}{l}\text { Giant cell arteritis (GCA) } \\
\text { Takayasu arteriitis (TA) }\end{array}$ \\
\hline Medium vessels & $\begin{array}{l}\text { Polyarteritis nodosa (PAN) } \\
\text { Kawasaki disease (KD) }\end{array}$ \\
\hline $\begin{array}{l}\text { Small vessels } \\
\text { ANCA-associated }\end{array}$ & $\begin{array}{l}\text { Granulomatosis with polyangiitis (GPA) } \\
\text { Microscopic polyangiitis (MPA) } \\
\text { Eosinophilic granulomatosis with poly- } \\
\text { angiitis (EGPA) }\end{array}$ \\
\hline $\begin{array}{l}\text { Small vessels } \\
\text { associated with immune } \\
\text { complexes }\end{array}$ & $\begin{array}{l}\text { Cryoglobulin associated vasculitis (CV) } \\
\text { Behcet's disease (BD) } \\
\text { Connective tissue disease } \\
\text { Systemic lupus erythematosus (SLE) } \\
\text { Mixed connective tissue disease (MCTD) } \\
\text { Sjogren syndrome (SS) }\end{array}$ \\
\hline
\end{tabular}

meningoencephalitis. In contrast, vasculitides as a manifestation of bacterial and/or fungal meningoencephalitis were excluded, as imaging, treatment, and particularly the time course, prognosis and thus follow-up regimes for these conditions differ significantly from the included conditions. The clinical, laboratory, imaging and neuropathological data of each patient were evaluated. Relevant clinical and laboratory findings included the clinical presentation, patient age, the presence of CNS inflammation evidenced by cerebrospinal fluid exams, serologic results including parameters for systemic collagenosis and vasculitis, other evidence of systemic disease and cardiovascular risk profile. Available imaging exams [MRI, MRA, DSA, computed tomography (CT), positron-emission tomography-computed tomography (PET-CT)] were assessed for the presence, distribution and age of ischemic or hemorrhagic brain lesions, cerebral parenchymal or meningeal contrast enhancement, irregularities, stenoses or occlusions of intracranial arteries and signs of systemic vasculitis. The available neuropathological reports on brain and/or meningeal biopsies were reviewed. Patients were included for further analysis if a diagnosis of definite or probable CNS vasculitis could thus be established. Regarding PACNS, diagnoses were made according to the work-flow suggested by Berlit and Krämer [3]. This work-flow was developed with regard to the diagnostic criteria of PACNS developed by Birnbaum and Hellmann in their 2009 revision [7] of the Calabrese and Mallek criteria [11] (for details see Fig. 1). Patients were categorized according to the affected vessel size as proposed by Küker [26]: DSA-negative patients were classified as having small-vessel CNS vasculitis while patients with stenoses visualized on DSA and/or MRI were classified as having large- and/or medium-sized vessel CNS vasculitis. The large/medium vessel CNS vasculitis group was further subdivided in patients 


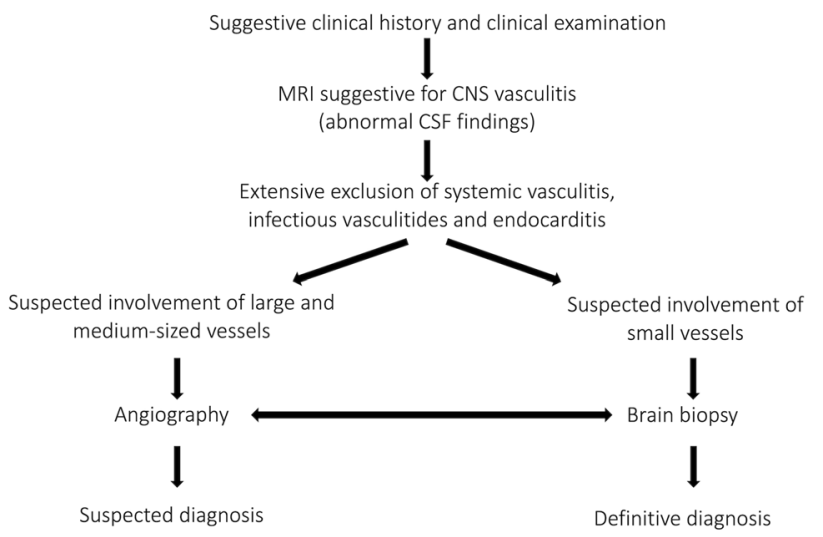

Fig. 1 Flow chart on the diagnostic work-up for PACNS (adapted from Berlit and Kraemer [3]; Birnbaum and Hellmann [7])

with pathologic findings (luminal irregularities, stenoses, occlusions) visible on MR angiography ("MRA-positive") and patients with luminal abnormalities only depicted by DSA ("MRA-negative").

Subsequently a search of the identified patients in the local Picture Archiving and Communication System (PACS) was performed. Patients who had at least one MRI scan including dedicated vessel wall imaging were included in the study.

\section{MRI protocol}

$89 \%$ of the analyzed MRI scans were acquired on a 3 Tesla Signa Excite scanner (GE Healthcare, Milwaukee, WI, USA), $8 \%$ on a 3 Tesla Magnetom Verio scanner (Siemens Healthineers, Erlangen, Germany) and 3\% on a 1.5 Tesla Magnetom Aera scanner (Siemens Healthineers, Erlangen, Germany). The 1.5 Tesla scanner was used for one patient with a cardiac pacemaker not approved for 3 Tesla.

Vessel wall imaging was performed using a fat- and blood-suppressed 2D double inversion recovery spin-echo T1-weighted sequence pre- and post contrast. The sequences were acquired in axial and coronary planes with a slice thickness of $2 \mathrm{~mm}$. Depending on the scanner, the in-plane resolution was $0.5 \times 0.5 \mathrm{~mm}$ (Signa), $0.4 \times 0.4 \mathrm{~mm}$ (Verio) or $0.9 \times 0.9 \mathrm{~mm}$ (Aera). Eight to 14 slices were positioned to include the most prominent stenoses as visualized by Time-of-Flight-MRA. If there were no obvious stenoses, the sequences were positioned to cover the Circle of Willis.

The imaging protocols further included diffusionweighted imaging (DWI), fluid-attenuated inversion recovery (FLAIR), T2* or susceptibility-weighted imaging (SWI) and, in most cases, contrast-enhanced MR angiography and a 3D T1-weighted sequence pre- and post contrast.

\section{Image analysis}

Of each patient, all MRI scans including vessel wall imaging acquired within the first two years after initial presentation to our hospital and the last available MRI scan were evaluated. The timing of the initial vessel wall imaging examinations in respect to the time of presentation to our institution as well as the start of immunosuppressive therapy was documented. Follow-up intervals were categorized as "shortterm" (within three months after the first MRI with vessel wall imaging), "mid-term" (3-12 months) and "long-term" (>12 months).

All stenoocclusive lesions depicted on vessel wall imaging were recorded by correlating vessel wall imaging with MRA sequences. The lesions were graded by visual inspection of MRA as $1=$ slight narrowing and irregularity of the lumen (estimated stenosis grade $<30 \%$ ); $2=$ moderate stenosis $(30-69 \%) ; 3=$ high-grade stenosis $(70-99 \%)$ or $4=$ occlusion. For each depicted stenoocclusive lesion, the degree of vessel wall contrast enhancement was documented as either $0=$ no enhancement, $1=$ moderate enhancement or $2=$ strong enhancement as defined and shown by Pfefferkorn et al. [29]. Vessel wall contrast enhancement without stenosis was also recorded. Furthermore, the morphology of contrast enhancement on the initial MRI scan was classified as either concentric or eccentric. This classification was performed as previously described by Obusez et al. [25]: Enhancement was recorded as concentric if it was uniform and involved the entire circumference of the arterial wall and as eccentric if it was nonuniform, mainly on one side of the arterial wall and not involving the entire circumference. DWI was examined and diffusion-restricted lesions signifying acute ischemic infarctions were identified. The diffusionrestricted lesions were recorded according to their location in relation to the stenoses depicted on vessel wall imaging, i.e. whether they were sited in a territory supplied by a stenotic artery. In patients with contrast-enhancing vessel wall lesions, each follow-up MRI scan with vessel wall imaging was compared to the previous exam and regression, stability or progression of each contrast-enhancing vessel wall lesion was reported. Newly occurred contrast-enhancing vessel wall lesions were recorded as progression. Lesions which continued to display complete resolution of vessel wall contrast enhancement were categorized together with regressive contrast-enhancing vessel wall lesions. Diffusionrestricted lesions were also recorded on follow-up.

Vessel wall imaging on initial presentation and followup was analyzed by two neuroradiologists separately and blinded to other imaging and clinical findings. Discrepant reading results were resolved in consensus. 


\section{Clinical analysis}

The medical records of each patient were evaluated and clinical parameters were documented for each patient at the time of each MRI examination. At baseline, the onset of symptoms (i.e. acute versus subacute), the range of neurological symptoms (i.e. headache, focal neurological deficits, cognitive/behavioral changes, newly occurring symptomatic epilepsy/epileptic seizures) and the National Institute of Health Stroke Scale (NIHSS) Score were documented. At each follow-up, the range of neurological symptoms and the NIHSS were again documented (for details see Table 2, Suppl. 1).

Additionally, on follow-up, the clinical status was recorded as either "stable disease/remission" or "relapse". A relapse was defined according to Salvarani et al. [30] as either a recurrence of or worsening of symptoms of CNS vasculitis and/or evidence of new diffusion-restricted lesions or an increase of ischemic lesions on MRI. A relapse usually was associated with an increase in immunotherapy (see Table 2).

Treatment of CNS vasculitis with steroids and/or other immunosuppressive agents was documented at initial presentation and at the time of each MRI examination.

\section{Statistical analysis}

Categorical variables were analyzed using two-sided Fisher's exact test. To evaluate the course of vessel wall imaging findings in relation to clinical findings, the three possible vessel wall imaging outcomes (progressive, stable or regressive/no vessel wall contrast enhancement) were dichotomized in two different ways and compared to the clinical status of "remission" or "relapse", also using twosided Fisher's exact test. $P$ values $<0.05$ were considered significant. Statistical analyses were performed using SPSS Statistics version 25 (IBM, Armonk, NY, USA).

\section{Results}

\section{Population}

45 Patients were included in the study. 27 patients were female and 18 were male. The median age was 58 years (range 19-75 years).

Initially, 15 patients were classified as small-vessel CNS vasculitis and 30 patients as large/medium vessel CNS vasculitis. In 28 of the patients with large/medium vessel CNS vasculitis, stenoses or irregularities of intracranial arteries were visualized on MR angiography ("MRA-positive") while two patients showed abnormalities of medium-sized arteries on DSA only ("MRA-negative"). Consequently, 17 patients were initially categorized as MRA-negative and 28 as MRA-positive. Figure 2 shows the distribution of patients in the different study groups. Table 2 summarizes epidemiological and clinical data, diagnoses and treatment of the patient group.

Forty of 45 patients received their first MRI scan including vessel wall imaging within three months of the initial presentation to our institution. The other five patients were initially examined within four to eight months. Forty-four of the 45 patients were not under immunosuppressive therapy at the time of the first presentation to our hospital. All 23 patients with follow-up evaluations (see below) had their initial vessel wall imaging within four weeks of the initial presentation and none of these patients had received immunosuppression at initial presentation.

\section{Initial presentation}

\section{MRA-negative patients}

15 of the 17 patients $(88.2 \%)$ did not show any vessel wall contrast enhancement. Two patients (11.8\%) presented with vessel wall contrast enhancement of large arteries without stenosis.

\section{MRA-positive patients}

28 patients harbored 67 stenoocclusive lesions examined by vessel wall imaging. The degree of stenosis was graded as " 1 " in eight cases (11.9\%), " 2 " in 26 cases (38.8\%), " 3 " in 25 cases $(37.3 \%)$ and " 4 " in seven cases (10.4\%).

53 of the stenoocclusive lesions (79.1\%) showed vessel wall contrast enhancement. Vessel wall contrast enhancement without stenosis was found in seven vessel segments in five patients. Any vessel wall contrast enhancement was seen in all patients (100\%). Vessel wall contrast enhancement was graded as strong in $51.7 \%(31 / 60)$ and as moderate in $48.3 \%$ (29/60) of cases. Vessel wall contrast enhancement was further classified as concentric in $88.3 \%(53 / 60)$ and as eccentric in $11.7 \%(7 / 60)$ of cases.

\section{Group comparison}

The presence of any vessel wall contrast enhancement was significantly more frequent in MRA positive vs. MRA-negative patients $(p<0.0001)$ and in large/medium-vessel CNS vasculitis vs. small-vessel CNS vasculitis $(p<0.0001)$. 
Table 2 Characteristics of the study population

$n=45, \mathrm{f} / \mathrm{m} 1.5: 1,58$ y [19-75] (median [range])

Medium/large-vessel vasculitis

$66.7 \%(n=30)$

55 y [19-75]

$\mathrm{f} / \mathrm{m} \mathrm{1.3:1}$

Etiology/diagnosis

PACNS

Systemic autoimmune vasculitis with CNS involvement

Giant cell arteriitis

Systemic lupus

Unclassified systemic vasculitis

(Para)infectious CNS vasculitis

HIV/Lues

HSV-1

HHV-6

Type of onset

Acute (stroke-like)

Subacute (days to weeks)

Chronic progressive (months)

Symptoms at onset

Headache

Neuropsychiatric complaints

Epilepsy/seizures

(Multi)focal deficits

Relapses (of $n=21$ patients with 48 follow-up evaluations)

Overall number of relapses

Clinical worsening and new DWI lesions

New DWI lesions only

Clinical worsening only

Number of patients with relapses

Clinical worsening and new DWI lesions

New DWI lesions only

Clinical Worsening only

Immunosuppression (of $n=21$ patients with 48 follow-up evaluations)

Overall

Steroids

Other immunotherapies

Combination of steroids plus one additional immunosuppressant

Combination of steroids plus $>1$ additional immunosuppressant

Increase of immunotherapies in relapse

Small vessel vasculitis
$63.3 \%(\mathrm{n}=19)$

$26.7 \%(n=8)$

$16.7 \%(n=5)$

$3.3 \%(n=1)$

$6.6 \%(n=2)$

$10.0 \%(n=3)$

$3.3 \%(n=1)$

$3.3 \%(n=1)$

$3.3 \%(n=1)$

$66.7 \%(n=20)$

$33.3 \%(n=10)$

$0.0 \%(n=0)$

$43.3 \%(n=13)$

$16.7 \%(n=5)$

$0.0 \%(n=0)$

$66.7 \%(n=20)$

NIHSS 2 [0-12]

$33.3 \%(16 / 48)$

$14.5 \%(7 / 48)$

$6.3 \%(3 / 48)$

$12.5 \%(6 / 48)$

$52.4 \%(11 / 21)$

$33.3 \%(7 / 21)$

$4.8 \%(1 / 21)$

$19.0 \%(4 / 21)$

$95.0 \%(20 / 21)$

$95.0 \%(20 / 21)$

$66.7 \%(14 / 21)$

Cyc $(n=8)$, Aza $(n=5), \operatorname{MTX}(n=3)$, RTX

$(n=2)$, Toc $(n=2)$

$71.4 \%(15 / 21)$

$9.5 \%(2 / 21)$

$100 \%$ (16/16 relapses in $11 / 11$ patients $)$

$33.3 \%(n=15)$

$\mathrm{f} / \mathrm{m} 2: 1$
52 y [19-75]

60.5 y [38-74]

66 y [59-74]

$38 \mathrm{y}$

41,52 y

57 y [53-68]

$68 \mathrm{y}$

$57 \mathrm{y}$

$53 \mathrm{y}$

Etiology/diagnosis

PACNS

ANCA-associated systemic vasculitis mPA

GPA

Systemic lupus

Other autoimmune etiology

CREST
$46.7 \%(n=7)$

$20.0 \%(n=3)$

$13.3 \%(n=2)$

$6.7 \%(n=1)$

$13.3 \%(n=2)$

$20.0 \%(n=3)$

$6.7 \%(n=1)$
62 y [46-74]

73 y [44-75]

$73,75 \mathrm{y}$

$44 \mathrm{y}$

$24,69 \mathrm{y}$

62 y [54-67]

$67 \mathrm{y}$ 
Table 2 (continued)

\begin{tabular}{|c|c|c|}
\hline Small vessel vasculitis & $\begin{array}{l}33.3 \%(n=15) \\
\mathrm{f} / \mathrm{m} 2: 1\end{array}$ & 62 y [24-75] \\
\hline Sjögren & $6.7 \%(n=1)$ & $54 \mathrm{y}$ \\
\hline CAPS & $6.7 \%(n=1)$ & $61 \mathrm{y}$ \\
\hline \multicolumn{3}{|l|}{ Type of onset } \\
\hline Acute (stroke-like) & $26.7 \%(n=4)$ & \\
\hline Subacute (days to weeks) & $66.7 \%(n=10)$ & \\
\hline Chronic progressive (months) & $6.7 \%(n=1)$ & \\
\hline \multicolumn{3}{|l|}{ Symptoms } \\
\hline Headache & $53.3 \%(n=8)$ & \\
\hline Neuropsychiatric complaints & $46.7 \%(n=7)$ & \\
\hline Epilepsy/seizures & $6.7 \%(n=1)$ & \\
\hline (Multi)focal deficits & $\begin{array}{l}80.0 \%(n=12) \\
\text { NIHSS } 3[0-7]\end{array}$ & \\
\hline \multicolumn{3}{|l|}{ Relapses (of $n=2$ patients with 7 follow-up evaluations) } \\
\hline Overall number of relapses & $42.9 \%(3 / 7)$ & \\
\hline Clinical worsening and new DWI lesions & $14.2 \%(1 / 7)$ & \\
\hline New DWI lesions only & $0 \%(0 / 7)$ & \\
\hline Clinical worsening only & $28.6 \%(2 / 7)$ & \\
\hline Number of patients with relapses & $100 \%(2 / 2)$ & \\
\hline \multicolumn{3}{|l|}{ Clinical worsening and new DWI lesions } \\
\hline New DWI lesions only & $0 \%(0 / 2)$ & \\
\hline Clinical worsening only & $50.0 \%(1 / 2)$ & \\
\hline \multicolumn{3}{|l|}{ Immunosuppression } \\
\hline Overall & $100 \%(2 / 2)$ & \\
\hline Steroids & $100 \%(2 / 2)$ & \\
\hline Other immunotherapies & $\begin{array}{l}100 \%(2 / 2) \\
\operatorname{RTX}(n=1), \operatorname{MTX}(n=1), \text { Anakinra }(n=1)\end{array}$ & \\
\hline Combination of steroids plus one additional immunosuppressant & $50 \%(1 / 2)$ & \\
\hline Combination of steroids plus $>1$ additional immunosuppressant & $50 \%(1 / 2)$ & \\
\hline Increase of immunotherapies in relapse & $100 \%$ ( $3 / 3$ relapses in $2 / 2$ patients $)$ & \\
\hline
\end{tabular}

$f$ female, $m$ male, $y$ years, Aza azathioprine, CAPS cryoporine-associated periodic (fever) syndrome, CREST calcinosis cutis/raynaud syndrome/ esophagus involvement/sclerodermia/teleangiectasia, $D W I$ diffusion-weighted imaging, GPA granulomatosis with polyangiitis, $H H V-6$ human herpes virus type 6, HIV human immunodeficiency virus, $H S V$ herpes simplex virus, $m P A$ microscopic polyangiitis, $M T X$ methotrexate, $M M F$ mycophenolate-mofetil, PACNS primary angiitis of the central nervous system, $R T X$ rituximab, Toc tocilizumab

\section{Correlation of vessel wall imaging and diffusion-weighted imaging}

Associated diffusion-restricted lesions were found significantly more often $(p=0.048)$ in stenoses with vessel wall contrast enhancement $(18 / 50,36.0 \%)$ than in stenoses without vessel wall contrast enhancement $(1 / 14,7.1 \%)$. Three stenoses were excluded from this analysis because their association to existing diffusion-restricted lesions could not clearly be determined. Diffusion-restricted lesions unrelated to visible stenoses were found in 13 patients.

\section{Follow-up}

\section{Vessel wall imaging}

Twenty-three patients with 48 contrast-enhancing vessel wall lesions had follow-up MRI scans including vessel wall imaging. This comprised seven contrast-enhancing vessel wall lesions that developed during follow-up. 55 MRI scans were analyzed ( $n=1-6$ per patient) and 120 assessments of contrast-enhancing vessel wall lesions were performed overall. The length of follow-up ranged from 7 to 3543 days (Median 239.5 days). 
Fig. 2 Distribution of patients to the different subgroups of the study

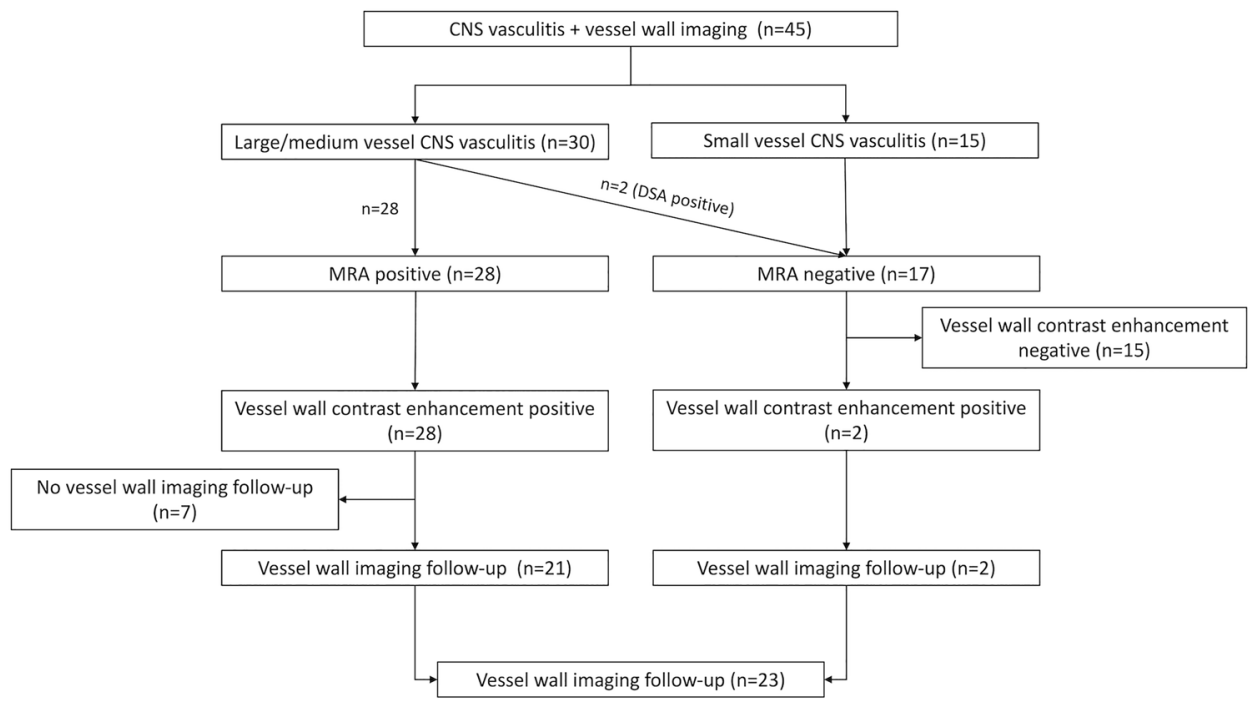

Per contrast-enhancing vessel wall lesion and MRI scan, vessel wall contrast enhancement was graded as progressive in $10 / 120$ cases $(8.3 \%$ ), as stable in $52 / 120$ cases $(43.3 \%$ ) and as regressive/no enhancement in 58/120 cases (48.3\%).

Per patient and MRI scan, vessel wall imaging was rated as progressive in $5 / 55$ cases (9.1\%), as stable in $25 / 55$ cases $(45.5 \%)$ and as regressive/no enhancement in $25 / 55$ cases $(45.5 \%)$.

Short-term follow-up ( $<3$ months) was available for 16 patients harboring 34 contrast-enhancing vessel wall lesions. Per patient, vessel wall imaging was graded as progressive in one case $(6.3 \%)$, as stable in seven cases $(43.8 \%)$ as regressive/no enhancement in 8 cases $(50.0 \%)$.

Mid-term follow-up (3-12 months) was available for 13 patients harboring 22 contrast-enhancing vessel wall lesions. Per patient, vessel wall imaging was graded as progressive in no case $(0 \%)$, as stable in three cases $(23.1 \%)$ and as regressive/no enhancement in ten cases (76.9\%).

Long-term follow-up ( $>12$ months) was available for 9 patients harboring 19 contrast-enhancing vessel wall lesions. Per patient, vessel wall imaging was graded as progressive in three cases (33.3\%), as stable in one case (11.1\%) and as regressive/no enhancement in five cases $(55.6 \%)$.
Table 3 shows the evolution of contrast-enhancing vessel wall lesions overall and at the different predefined time intervals. Figures 3, 4, 5 show examples of stable, regressive and progressive vessel wall imaging findings.

\section{Diffusion-restricted lesions}

Diffusion-restricted lesions were found in nine of 23 patients and in eleven of the 55 follow-up MRI scans. On nine MRI scans, diffusion-restricted lesions were associated with a contrast-enhancing vessel wall lesion while on two scans, diffusion-restricted lesions were unrelated to contrastenhancing vessel wall lesions (no statistically significant difference).

\section{Clinical parameters and therapy}

One patient with one follow-up MRI did not receive specific treatment. 22 patients with 54 MRI scans were under steroid and/or immunosuppressive treatment for the length of follow-up (see Table 2).
Table 3 Evolution of vesselwall contrast enhancement on follow-up

\begin{tabular}{lllll}
\hline Follow-up interval & $\begin{array}{l}\text { Complete resolu- } \\
\text { tion of VW-CE }\end{array}$ & $\begin{array}{l}\text { Partial regres- } \\
\text { sion of VW-CE }\end{array}$ & Stability of VW-CE & $\begin{array}{l}\text { Progression } \\
\text { of VW-CE }\end{array}$ \\
\hline Entire Follow-up* $(N=48)^{* *}$ & $13(27.1 \%)$ & $14(29.2 \%)$ & $17(35.4 \%)$ & $4(8.3 \%)$ \\
Short-term $(N=34)^{* *}$ & $2(5.9 \%)$ & $12(35.3 \%)$ & $19(55.9 \%)$ & $1(2.9 \%)$ \\
Mid-term $(N=22)^{* *}$ & $7(31.8 \%)$ & $9(40.9 \%)$ & $6(27.3 \%)$ & $0(0 \%)$ \\
Long-term $(N=21)^{* *}$ & $8(38.1 \%)$ & $6(28.6 \%)$ & $3(14.3 \%)$ & $4(19.0 \%)$ \\
\hline
\end{tabular}

$V W-C E$ vessel wall contrast enhancement

*Comparison of the initial MRI scan with the last available MRI scan of each patient

**Number of evaluated VW-CE lesions 

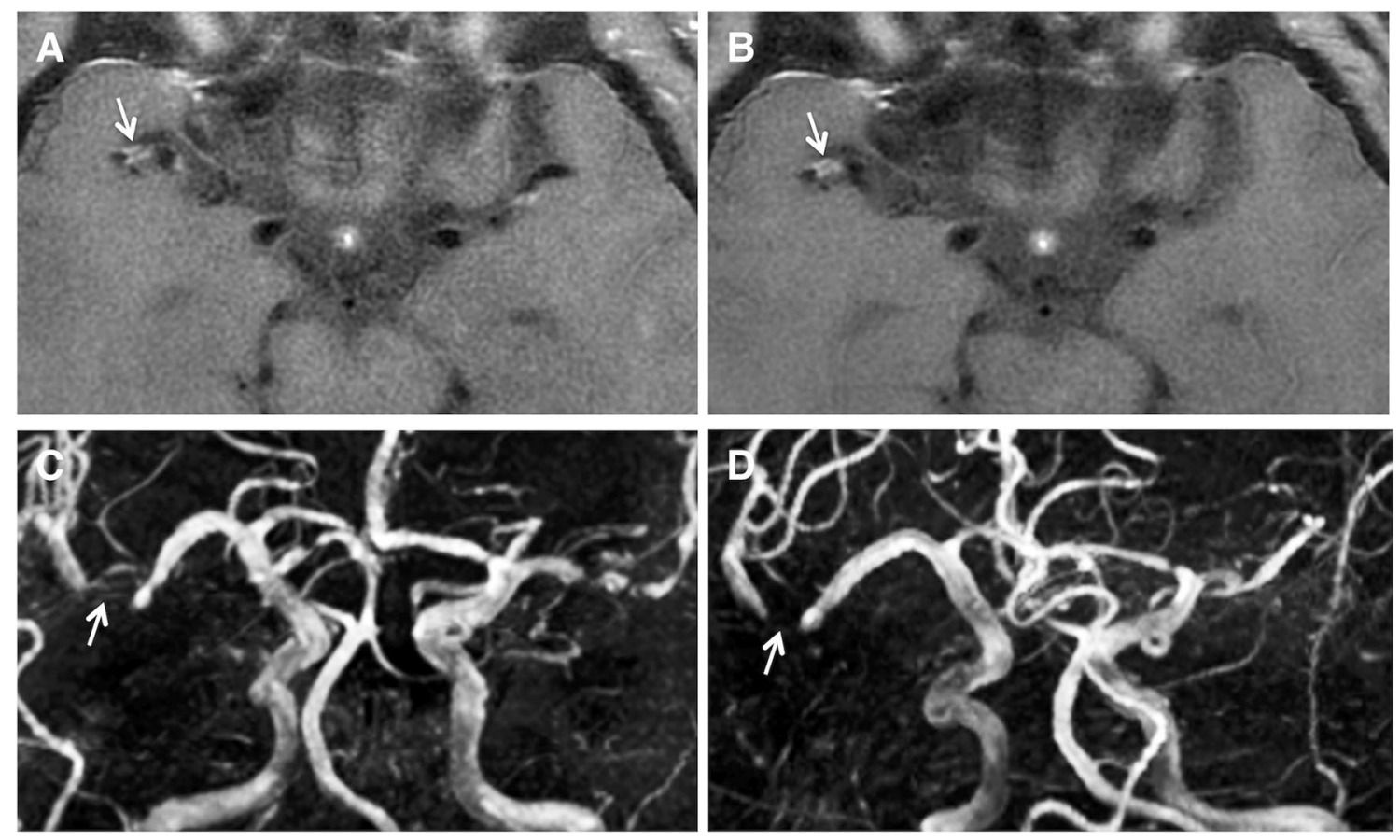

Fig. 3 Stable vessel wall imaging findings on follow-up in a patient with PACNS. Vessel wall contrast enhancement of the right distal M1 segment is seen at initial presentation on vessel wall imaging

The status of the patients at the time of the follow-up MRI scans was assessed as "stable/in remission" on 36/55 occasions (65.5\%) and as "relapse" on 19/55 occasions (34.5\%).

On occasions with progressive vessel wall contrast enhancement on follow-up $(n=5)$, the clinical status was "remission" in two cases (40.0\%) and "relapse" in three cases (60.0\%). When vessel wall contrast enhancement was stable $(n=25)$, the clinical status was "remission" in 14 cases $(56.0 \%)$ and "relapse" in eleven cases (44.0\%). In cases with no vessel wall contrast enhancement or regression of vessel wall contrast enhancement findings $(n=25)$, the clinical status was "remission" in 20 cases (80.0\%) and "relapse" in five cases (20.0\%).

A relapse was found significantly less often $(p=0.0495)$ in cases with no or regressive vessel wall contrast enhancement (5/25 cases) compared to cases with stable or progressive vessel wall contrast enhancement (14/30 cases). There was no significant difference $(p=0.3273)$ regarding the frequency of relapses when pooling cases with no or regressive and stable vessel wall contrast enhancement (16/50 cases) and comparing them to cases with progressive vessel wall contrast enhancement findings ( $3 / 5$ cases).
(A), which remains unchanged at two-months follow-up (B) despite immunosuppressive therapy. Correlating TOF-MRA findings $(\mathbf{C}, \mathbf{D})$, showing unchanged high-grade stenosis of the affected segment

\section{Discussion}

Regarding the findings at the time of initial presentation of the patients, the results of our study corroborate several common assumptions about vessel wall imaging in patients with CNS vasculitis. Any vessel wall contrast enhancement was reported by Küker et al. in $85.2 \%$ and by Thaler et al. in $60.9 \%$ of cases with large/medium vessel CNS vasculitis [22, 23]. In our study, more than three quarters of the depicted stenoses showed vessel wall contrast enhancement and any vessel wall contrast enhancement was found in each of the MRA-positive patients. Thus we confirmed that vessel wall contrast enhancement is a frequent finding in patients with large/medium vessel CNS vasculitis. However, it is important to be aware that vessel wall contrast enhancement is not exclusive to vasculitis but can also occur in various other pathologies. Based on an overview of differential diagnoses of PACNS published in a recent review article [31], we compiled a list of different subtypes of central nervous system vasculitis as 

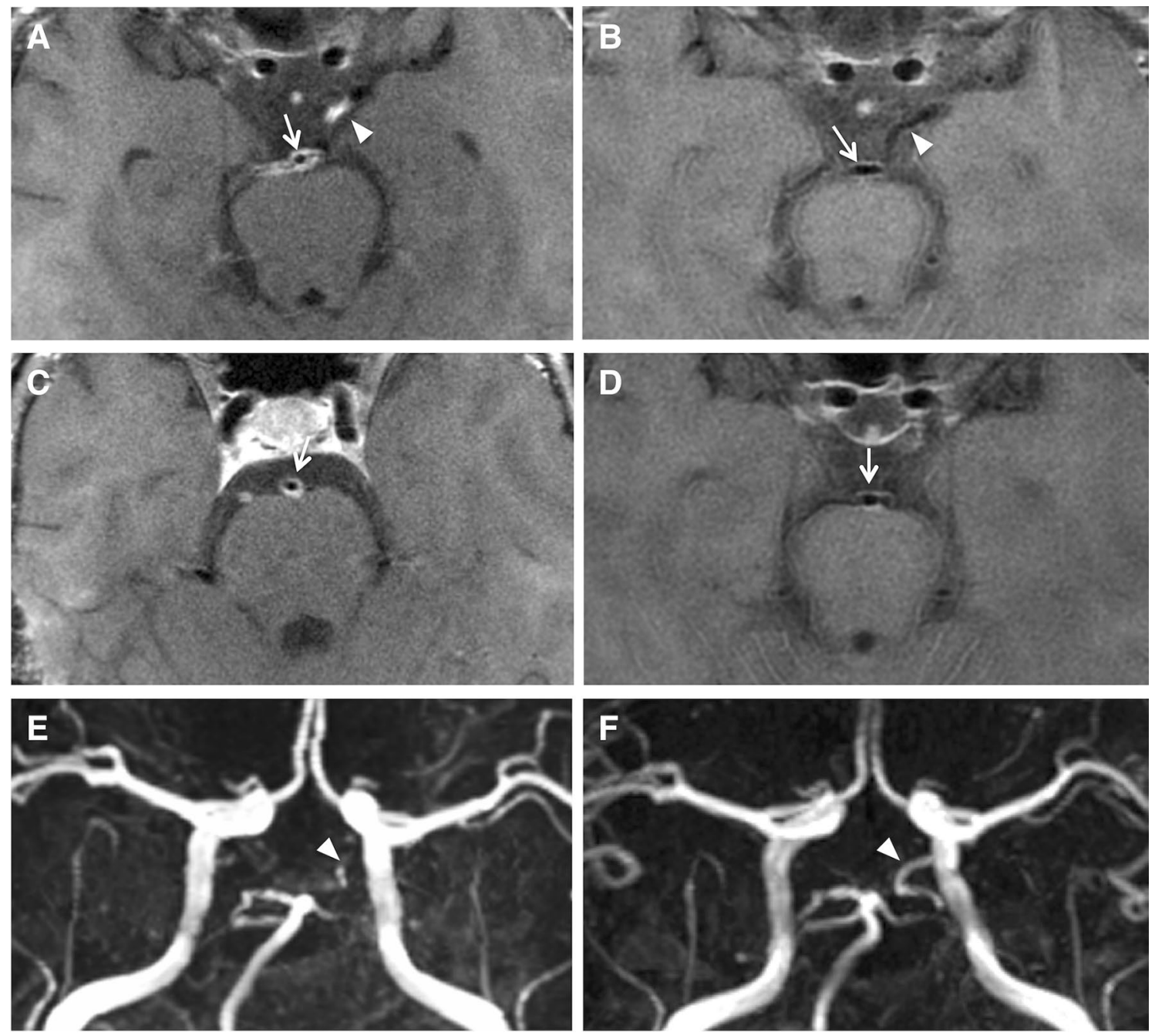

Fig. 4 Regressive vessel wall imaging findings on follow-up in a patient with PACNS. At initial presentation $(\mathbf{A}, \mathbf{C})$, there is marked vessel wall contrast enhancement of the posterior circulation, including the basilar artery (arrow) and left posterior communicating artery (arrowhead). Follow-up vessel wall imaging after ten years $(\mathbf{B}, \mathbf{D})$ shows complete resolution of vessel wall contrast enhancement of the posterior communicating artery and regressive but still persistent ves-

well as possible differential diagnoses in which vessel wall contrast enhancement has been reported in the literature (see Table 4). From this list it becomes clear that a diagnosis of central nervous system vasculitis cannot be based simply on the presence of vessel wall contrast enhancement. Important potential mimicks of central nervous system vasculitis in which vessel wall contrast enhancement has been shown, at least to a lesser extent, include atherosclerosis, moyamoya disease and reversible cerebral vasoconstriction syndrome (RCVS) [32-36]. However, the morphologic characteristics of vessel wall contrast enhancement could be helpful in distinguishing between distinct vasculopathies. Vasculitis is usually considered to result in concentric wall-thickening and enhancement as sel wall contrast enhancement of the basilar artery. Correlating TOFMRA images $(\mathbf{E}, \mathbf{F})$ demonstrate resolution of a high-grade stenosis of the left posterior communicating artery. The findings after ten years are unchanged compared to a six months follow-up scan (not shown). The patient was under immunosuppressive therapy for the whole follow-up period

opposed to eccentric plaque enhancement in atherosclerosis $[18,19]$. Our findings support this assumption, as $90 \%$ of vessel wall contrast enhancements were classified as "concentric". This also shows, however, that eccentric vessel wall contrast enhancement can occur in CNS vasculitis in a minority of cases, thus potentially further complicating the differentiation from atherosclerosis. Our results in this regard corroborate the findings of Obusez et al. [25] who reported eccentric wall abnormality in three of twelve CNS vasculitis cases. Further research is needed to define the role of vessel wall imaging in differentiating central nervous system vasculitis from other vasculopathies.

Thaler et al. [23] compared MRI features of large-vessel PACNS and small-vessel PACNS and found significant 

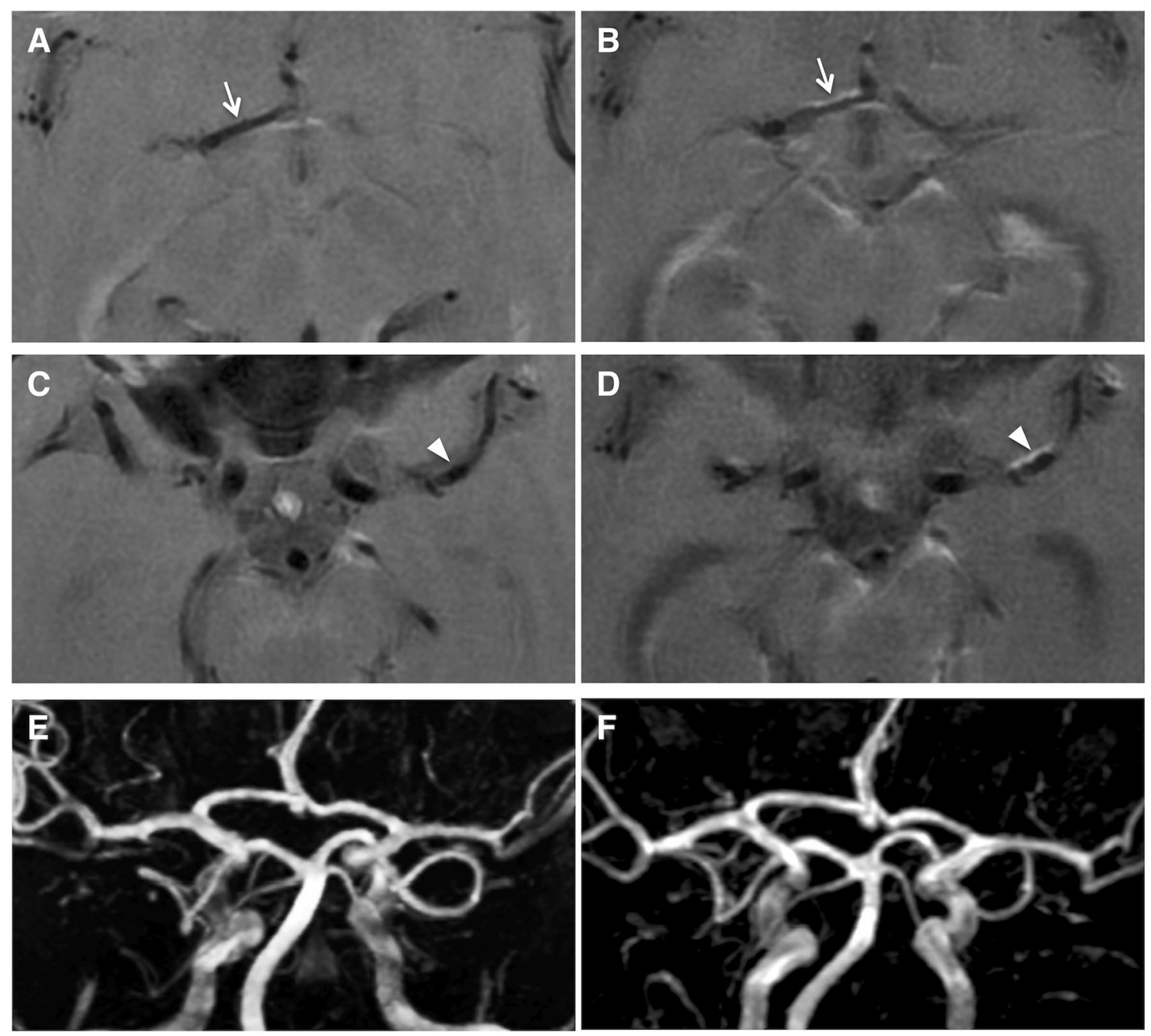

Fig. 5 Progressive vessel wall imaging findings on follow-up in a patient with CNS vasculitis due to cryopyrin-associated periodic syndrome. Follow-up vessel wall imaging performed 34 months after the initial presentation $(\mathbf{B}, \mathbf{D})$ depicts contrast enhancement along the anterior vessel walls of the right A1 segment (arrow) and the left M1 segment (arrowhead), which was not identifiable on the initial MRI

differences regarding the frequency of vessel wall contrast enhancement, reporting no vessel wall contrast enhancement in six patients with small-vessel PACNS. Our results are in agreement, as vessel wall contrast enhancement was also found significantly less often in small-vessel CNS vasculitis ( 2 of 17 cases) than in large/medium vessel CNS vasculitis. It is not a surprising result, as the spatial resolution of MRI might be too low to assess very small arteries/ arterioles which cannot be evaluated on DSA. Moreover, our vessel wall imaging sequences were placed to depict large- and medium-sized arteries. However, it is an indication that vessel wall imaging usually will not show signs of large-/medium-sized vessel inflammation which is "invisible" on luminal imaging in patients with small-vessel CNS scan $(\mathbf{A}, \mathbf{C})$. Perivascular contrast enhancement surrounding the posterior cerebral arteries can be seen on both scans. Correlating TOFMRA images $(\mathbf{E}, \mathbf{F})$ at both times do not show stenoses of the arteries of the circle of Willis ("MRA-negative"). The patient was under immunosuppressive therapy for the follow-up period

vasculitis. In our group, though, there were also two exceptions to that rule. In particular, there was one patient with cryopyrin-associated periodic syndrome (CAPS) who did not show obvious changes of large- or medium-sized arteries but presented with ischemic stroke and marked perivascular contrast enhancement of arteries of the circle of Willis (see Fig. 5). This underlines the heterogeneity of the spectrum of inflammatory vasculopathies, which makes generally applicable statements difficult.

In our group of CNS vasculitis patients, diffusionrestricted lesions were associated with vessel wall contrast enhancement of stenoocclusive lesions at initial presentation. This observation suggests that vessel wall contrast enhancement represents a condition of the vessel wall that 
Table 4 Reports of intracranial vessel wall contrast enhancement in central nervous system vasculitis and its differential diagnoses

\begin{tabular}{|c|c|}
\hline Disease & $\begin{array}{l}\text { Reports of intracranial vessel wall } \\
\text { contrast enhancement (examples) }\end{array}$ \\
\hline Primary angiitis of the central nervous system & $\begin{array}{l}\text { Own data a ; Thaler et al. [23]; Mossa-Basha et al. [34]; Pfefferkorn et al. [29]; } \\
\text { Küker et al. [22] }\end{array}$ \\
\hline \multicolumn{2}{|l|}{ CNS vasculitis as part of a primary systemic vasculitis } \\
\hline Giant cell arteritis & Own data ${ }^{a}$; Poillon et al. [37]; Siemonsen et al. [38] \\
\hline ANCA-associated vasculitides & Own data $\mathrm{a}^{\mathrm{a}}$ \\
\hline \multicolumn{2}{|l|}{ Systemic autoimmune and rheumatic diseases } \\
\hline Neurosarcoidosis & Kobayashi et al. [39] \\
\hline Neuro-Behcet & Kaido et al. [40] \\
\hline Systemic Lupus erythematodes & Own data ${ }^{\text {a }}$; Sarbu et al. [41]; Takeshita et al. [42]; Küker et al. [22] \\
\hline Systemic sclerosis & Küker et al. [22] \\
\hline \multicolumn{2}{|l|}{ Other autoimmune diseases } \\
\hline Susac syndrome & Padrick et al. [43]; Yahyavi-Firouz-Abadi et al. [44] \\
\hline Cryopyrin-associated periodic syndrome & Own data ${ }^{\mathrm{a}}$ \\
\hline \multicolumn{2}{|l|}{ Infectious vasculopathies } \\
\hline Viral infections (e.g. VZV, HSV, HIV, SARS-CoV 2) & $\begin{array}{l}\text { Own data a } \text {, Lersy et al. [45]; Mossa-Basha et al. [34]; Cheng-Ching et al. [24], } \\
\text { Küker et al. [22] }\end{array}$ \\
\hline Basal meningitis caused by tuberculosis or fungal infections & Lu et al. [46]; Lopes et al. [47] \\
\hline Bacterial infection (e.g. borreliosis, lues) & Askar et al. [48]; Bäuerle et al. [49]; Kurian et al. [50]; Lebas et al. [51] \\
\hline Radiation-induced vasculopathy & Li et al. [52] \\
\hline \multicolumn{2}{|l|}{ Noninflammatory vasculopathies } \\
\hline RCVS & Chen et al. [32];Mossa-Basha et al. [34]; Obusez et al. [25] \\
\hline Atherosclerosis & $\begin{array}{l}\text { Mossa-Basha et al. [34]; Mossa-Basha et al. [33]; Skarpathiotakis et al. [35]; Lou } \\
\text { et al. [53] }\end{array}$ \\
\hline CADASIL & Goldstein et al. [54] \\
\hline Moyamoya angiopathy & Wang et al. [36]; Mossa-Basha et al. [33]; Ryoo et al. [55]; Kim et al. [56] \\
\hline \multicolumn{2}{|l|}{ Metabolic diseases } \\
\hline Fabry disease & Kong et al. [57] \\
\hline \multicolumn{2}{|l|}{ Malignant diseases } \\
\hline Vascular lymphoma & Schaafsma et al. [58] \\
\hline
\end{tabular}

${ }^{a}$ Vessel wall contrast enhancement reported in this study

predisposes to ischemic stroke. This in turn might indicate that vessel wall contrast enhancement initially represents active inflammation causing prothrombogenic changes in the vessel wall and/or progressive stenosis.

Vessel wall imaging has been suggested as a means to monitor disease activity and treatment response in patients with CNS vasculitis [19, 20, 59, 60]. Several case reports and figures in review articles have been published showing decreasing or completely resolving vessel wall contrast enhancement under immunosuppressive therapy [20, 21, 61, 62]. Moreover, a significant effect of corticosteroid treatment on vessel wall contrast enhancement of the superficial temporal artery in patients with giant cell arteritis has been shown [63]. However, Obusez et al. evaluated the follow-up of six CNS vasculitis patients receiving immunosuppressive treatment over a median period of 13.5 months and found resolution of enhancement in only two cases and stable enhancement in four cases
[25]. Furthermore, the vessel wall imaging study group of the American Society of Neuroradiology states that, according to their experience, "there may be a discordance between intracranial VW-MR imaging findings and the clinical impression of vasculitis disease activity" [19]. Our analysis of follow-up vessel wall imaging in 23 CNS vasculitis patients largely supports this statement. Twentytwo of 23 patients received immunosuppressive therapy for the length of follow-up, which is probably the reason why progressive vessel wall imaging findings were rare. Complete resolution, regression without disappearance and stability of vessel wall contrast enhancement were relatively evenly distributed. Thus, while some patients showed quite obvious treatment response, others exhibited continued enhancement with unclear significance. Even on long-term follow-up, spanning periods of roughly one to ten years, persistence of vessel wall contrast enhancement was a frequent finding (see Fig. 3). Patients with stable or 
progressive vessel wall imaging findings more frequently had relapses than patients with regressive or without vessel wall contrast enhancement. In principle, this is in line with the findings at initial presentation, suggesting that vessel wall contrast enhancement might represent active inflammation. Yet there were also many cases of patients with persisting vessel wall contrast enhancement who were in remission, indicating that vessel wall contrast enhancement is not per se associated with clinical disease activity. However, vessel wall contrast enhancement in CNS vasculitis patients in clinical remission might still represent otherwise covert active inflammation of the vessel wall, as has been shown in biopsies of patients with Takayasu arteritis [64]. Alternatively, persisting vessel wall contrast enhancement could be caused by post-inflammatory mural fibrosis with or without neovascularization, as it is found in so-called "healed" giant cell arteritis [65]. As histopathologic evidence from large- or medium-sized cerebral arteries is difficult to obtain, further empiric studies will have to show whether vessel wall contrast enhancement is useful in guiding therapeutic decisions, such as possible discontinuation of long-term immunosuppressive medication. As CNS vasculitis represents an inhomogeneous group of disorders, it is also plausible that vessel wall contrast enhancement could behave differently on follow-up and under therapy in different subtypes of the disease, such as PACNS, systemic vasculitis with cerebral involvement and virus-associated vasculitides. Overall, the significance of vessel wall contrast enhancement as a biomarker of inflammatory activity on follow-up of CNS vasculitis patients remains ambiguous.

Our study is limited by its retrospective design, which for example led to varying numbers and intervals of follow-up examinations. The study group was inhomogeneous regarding the different subtypes of CNS vasculitis. Although the diagnoses of vasculitis were based on a thorough review of the cases, most of them were clinical- and imaging-based, thus the inclusion of patients with non-inflammatory vasculopathies cannot be completely ruled out. This is a problem inherent in studies including large/medium vessel PACNS patients, as the minority of published large/medium vessel PACNS cases are biopsyproven $[1,6]$. The lack of a control/comparison group precluded assertions about the value of vessel wall imaging in differentiating CNS vasculitis from other intracranial vasculopathies in our study. Another important limitation of our cohort is that five of the 45 included patients received their initial vessel wall imaging more than three months after the initial clinical presentation. Thus the initial vessel wall imaging findings cannot be interpreted with certainty to be representative of a (sub)acute state of the disease in all patients. However, in all 23 patients with follow-up MRI scans this was the case.

\section{Conclusions}

Analyzing a comparably large group of patients, we found that concentric vessel wall contrast enhancement is common in large/medium vessel CNS vasculitis and rare in smallvessel CNS vasculitis. At initial presentation, vessel wall contrast enhancement of a stenosis was associated with an increased probability of ischemic stroke, supporting the assumption that vessel wall contrast enhancement might represent inflammatory activity. This is further substantiated by the fact that patients with stable or progressive vessel wall imaging findings on follow-up evaluations were more likely to have a relapse. However, persisting vessel wall contrast enhancement despite immunosuppressive therapy and clinical remission was also a frequent finding. Overall, follow-up vessel wall imaging findings and their clinical correlation proved ambiguous. Given the rarity of the disease, multicenter pooling of data in large patient registers will be necessary to determine whether vessel wall imaging has value in guiding treatment decisions in patients with CNS vasculitis.

Supplementary Information The online version contains supplementary material available at https://doi.org/10.1007/s00415-021-10683-7.

Funding Open Access funding enabled and organized by Projekt DEAL.

Availability of data and materials The data that support the findings of this study are available from the corresponding author on reasonable request.

Code availability (software application or custom code) Not applicable.

\section{Declarations}

Conflicts of interest The authors declare that they have no conflict of interest.

Consent to participate The need for informed consent was waived due to the retrospective nature of the study.

Consent for publication The need for informed consent was waived due to the retrospective nature of the study. The manuscript does not contain identifying details.

Ethical approval The study was approved by the ethics committee of the medical faculty of the Ludwig-Maximilians-University Munich and has therefore been performed in accordance with the ethical standards laid down in the 1964 Declaration of Helsinki and its later amendments. The need for informed consent was waived due to the retrospective nature of the study.

Open Access This article is licensed under a Creative Commons Attribution 4.0 International License, which permits use, sharing, adaptation, distribution and reproduction in any medium or format, as long as you give appropriate credit to the original author(s) and the source, provide a link to the Creative Commons licence, and indicate if changes were made. The images or other third party material in this article are 
included in the article's Creative Commons licence, unless indicated otherwise in a credit line to the material. If material is not included in the article's Creative Commons licence and your intended use is not permitted by statutory regulation or exceeds the permitted use, you will need to obtain permission directly from the copyright holder. To view a copy of this licence, visit http://creativecommons.org/licenses/by/4.0/.

\section{References}

1. Salvarani C, Brown RD Jr, Calamia KT, Christianson TJ, Weigand SD, Miller DV, Giannini C, Meschia JF, Huston J 3rd, Hunder GG (2007) Primary central nervous system vasculitis: analysis of 101 patients. Ann Neurol 62(5):442-451. https://doi.org/10.1002/ana. 21226

2. Scolding NJ, Wilson H, Hohlfeld R, Polman C, Leite I, Gilhus N, Force ECVT (2002) The recognition, diagnosis and management of cerebral vasculitis: a European survey. Eur J Neurol 9(4):343347. https://doi.org/10.1046/j.1468-1331.2002.00422.x

3. Berlit P, Kraemer M (2014) Cerebral vasculitis in adults: what are the steps in order to establish the diagnosis? Red flags and pitfalls. Clin Exp Immunol 175(3):419-424. https://doi.org/10.1111/cei. 12221

4. Kraemer M, Berlit P (2010) Systemic, secondary and infectious causes for cerebral vasculitis: clinical experience with 16 new European cases. Rheumatol Int 30(11):1471-1476. https://doi.org/ 10.1007/s00296-009-1172-4

5. Marsh EB, Zeiler SR, Levy M, Llinas RH, Urrutia VC (2012) Diagnosing CNS vasculitis: the case against empiric treatment. Neurologist 18(4):233-238. https://doi.org/10.1097/NRL.0b013 e 31825 c6d 23

6. Salvarani C, Brown RD Jr, Christianson TJH, Huston J 3rd, Giannini C, Hunder GG (2020) Long-term remission, relapses and maintenance therapy in adult primary central nervous system vasculitis: a single-center 35-year experience. Autoimmun Rev 19(4):102497. https://doi.org/10.1016/j.autrev.2020.102497

7. Birnbaum J, Hellmann DB (2009) Primary angiitis of the central nervous system. Arch Neurol 66(6):704-709. https://doi.org/10. 1001/archneurol.2009.76

8. Boulouis G, de Boysson H, Zuber M, Guillevin L, Meary E, Costalat V, Pagnoux C, Naggara O, French Vasculitis G (2017) Primary angiitis of the central nervous system: magnetic resonance imaging spectrum of parenchymal, meningeal, and vascular lesions at baseline. Stroke 48(5):1248-1255. https://doi.org/10. 1161/STROKEAHA.116.016194

9. Chu CT, Gray L, Goldstein LB, Hulette CM (1998) Diagnosis of intracranial vasculitis: a multi-disciplinary approach. J Neuropathol Exp Neurol 57(1):30-38. https://doi.org/10.1097/00005 072-199801000-00005

10. Kadkhodayan Y, Alreshaid A, Moran CJ, Cross DT 3rd, Powers WJ, Derdeyn CP (2004) Primary angiitis of the central nervous system at conventional angiography. Radiology 233(3):878-882. https://doi.org/10.1148/radiol.2333031621

11. Calabrese LH, Mallek JA (1988) Primary angiitis of the central nervous system. Report of 8 new cases, review of the literature, and proposal for diagnostic criteria. Medicine 67(1):20-39. https://doi.org/10.1097/00005792-198801000-00002

12. Hajj-Ali RA, Calabrese LH (2009) Central nervous system vasculitis. Curr Opin Rheumatol 21(1):10-18. https://doi.org/10.1097/ bor.0b013e32831cf5e6

13. Alreshaid AA, Powers WJ (2003) Prognosis of patients with suspected primary CNS angiitis and negative brain biopsy. Neurology
61(6):831-833. https://doi.org/10.1212/01.wnl.0000081047. 22043.ab

14. Duna GF, Calabrese LH (1995) Limitations of invasive modalities in the diagnosis of primary angiitis of the central nervous system. J Rheumatol 22(4):662-667

15. Miller DV, Salvarani C, Hunder GG, Brown RD, Parisi JE, Christianson TJ, Giannini C (2009) Biopsy findings in primary angiitis of the central nervous system. Am J Surg Pathol 33(1):35-43. https://doi.org/10.1097/PAS.0b013e318181e097

16. Torres J, Loomis C, Cucchiara B, Smith M, Messe S (2016) Diagnostic yield and safety of brain biopsy for suspected primary central nervous system angiitis. Stroke 47(8):2127-2129. https://doi. org/10.1161/STROKEAHA.116.013874

17. Stoecklein VM, Kellert L, Patzig M, Kupper C, Giese A, Ruf V, Weller J, Kreth FW, Schoberl F (2021) Extended stereotactic brain biopsy in suspected primary central nervous system angiitis: good diagnostic accuracy and high safety. J Neurol 268(1):367-376. https://doi.org/10.1007/s00415-020-10157-2

18. Alexander MD, Yuan C, Rutman A, Tirschwell DL, Palagallo G, Gandhi D, Sekhar LN, Mossa-Basha M (2016) High-resolution intracranial vessel wall imaging: imaging beyond the lumen. J Neurol Neurosurg Psychiatry 87(6):589-597. https://doi.org/10. 1136/jnnp-2015-312020

19. Mandell DM, Mossa-Basha M, Qiao Y, Hess CP, Hui F, Matouk C, Johnson MH, Daemen MJ, Vossough A, Edjlali M, Saloner D, Ansari SA, Wasserman BA, Mikulis DJ, Vessel Wall Imaging Study Group of the American Society of N (2017) Intracranial vessel wall MRI: principles and expert consensus recommendations of the american society of neuroradiology. AJNR Am J Neuroradiol 38(2):218-229. https://doi.org/10.3174/ajnr.A4893

20. Mossa-Basha M, Alexander M, Gaddikeri S, Yuan C, Gandhi D (2016) Vessel wall imaging for intracranial vascular disease evaluation. J Neurointerv Surg 8(11):1154-1159. https://doi.org/ 10.1136/neurintsurg-2015-012127

21. Lindenholz A, van der Kolk AG, Zwanenburg JJM, Hendrikse J (2018) The use and pitfalls of intracranial vessel wall imaging: how we do it. Radiology 286(1):12-28. https://doi.org/10.1148/ radiol.2017162096

22. Kuker W, Gaertner S, Nagele T, Dopfer C, Schoning M, Fiehler J, Rothwell PM, Herrlinger U (2008) Vessel wall contrast enhancement: a diagnostic sign of cerebral vasculitis. Cerebrovasc Dis 26(1):23-29. https://doi.org/10.1159/000135649

23. Thaler C, Kaufmann-Buhler AK, Gansukh T, Gansukh A, Schuster S, Bachmann H, Thomalla G, Magnus T, Matschke J, Fiehler J, Siemonsen S (2019) Neuroradiologic characteristics of primary angiitis of the central nervous system according to the affected vessel size. Clin Neuroradiol 29(1):37-44. https://doi.org/10. 1007/s00062-017-0622-8

24. Cheng-Ching E, Jones S, Hui FK, Man S, Gilden D, Bhimraj A, Uchino K (2015) High-resolution MRI vessel wall imaging in varicella zoster virus vasculopathy. J Neurol Sci 351(1-2):168-173. https://doi.org/10.1016/j.jns.2015.02.017

25. Obusez EC, Hui F, Hajj-Ali RA, Cerejo R, Calabrese LH, Hammad T, Jones SE (2014) High-resolution MRI vessel wall imaging: spatial and temporal patterns of reversible cerebral vasoconstriction syndrome and central nervous system vasculitis. AJNR Am J Neuroradiol 35(8):1527-1532. https://doi.org/10.3174/ajnr. A3909

26. Kuker W (2007) Cerebral vasculitis: imaging signs revisited. Neuroradiology 49(6):471-479. https://doi.org/10.1007/ s00234-007-0223-3

27. Berlit P, Krämer M, Consensus Group (2019) Cerebral involvement in systemic vasculitides: extracts from the guideline of the 
German neurological society. Neurol Res Pract 1:13. https://doi. org/10.1186/s42466-019-0016-2

28. Jennette JC, Falk RJ, Bacon PA et al (2013) 2012 Revised international chapel hill consensus conference nomenclature of vasculitides. Arthritis Rheum 65(1):1-11. https://doi.org/10.1002/art. 37715

29. Pfefferkorn T, Linn J, Habs M, Opherk C, Cyran C, Ottomeyer C, Straube A, Dichgans M, Nikolaou K, Saam T (2013) Black blood MRI in suspected large artery primary angiitis of the central nervous system. J Neuroimaging 23(3):379-383. https://doi.org/ 10.1111/j.1552-6569.2012.00743.x

30. Salvarani C, Brown RD Jr, Christianson T, Miller DV, Giannini C, Huston J 3rd, Hunder GG (2015) An update of the Mayo Clinic cohort of patients with adult primary central nervous system vasculitis: description of 163 patients. Medicine (Baltimore) 94(21):e738. https://doi.org/10.1097/MD.0000000000000738

31. Kraemer M, Berlit P (2021) Primary central nervous system vasculitis - An update on diagnosis, differential diagnosis and treatment. J Neurol Sci 424:117422. https://doi.org/10.1016/j. jns.2021.117422

32. Chen CY, Chen SP, Fuh JL, Lirng JF, Chang FC, Wang YF, Wang SJ (2018) Vascular wall imaging in reversible cerebral vasoconstriction syndrome - a 3-T contrast-enhanced MRI study. J Headache Pain 19(1):74. https://doi.org/10.1186/s10194-018-0906-7

33. Mossa-Basha M, de Havenon A, Becker KJ, Hallam DK, Levitt MR, Cohen WA, Hippe DS, Alexander MD, Tirschwell DL, Hatsukami T, Amlie-Lefond C, Yuan C (2016) Added value of vessel wall magnetic resonance imaging in the differentiation of moyamoya vasculopathies in a non-Asian cohort. Stroke 47(7):17821788. https://doi.org/10.1161/STROKEAHA.116.013320

34. Mossa-Basha M, Shibata DK, Hallam DK, de Havenon A, Hippe DS, Becker KJ, Tirschwell DL, Hatsukami T, Balu N, Yuan C (2017) Added value of vessel wall magnetic resonance imaging for differentiation of nonocclusive intracranial vasculopathies. Stroke 48(11):3026-3033. https://doi.org/10.1161/STROKEAHA. 117.018227

35. Skarpathiotakis M, Mandell DM, Swartz RH, Tomlinson G, Mikulis DJ (2013) Intracranial atherosclerotic plaque enhancement in patients with ischemic stroke. AJNR Am J Neuroradiol 34(2):299-304. https://doi.org/10.3174/ajnr.A3209

36. Wang M, Yang Y, Zhou F, Li M, Liu R, Guan M, Li R, He L, Xu Y, Zhang B, Zhu B, Zhao X (2017) The contrast enhancement of intracranial arterial wall on high-resolution MRI and its clinical relevance in patients with moyamoya vasculopathy. Sci Rep 7:44264. https://doi.org/10.1038/srep44264

37. Poillon G, Collin A, Benhamou Y, Clavel G, Savatovsky J, Pinson C, Zuber K, Charbonneau F, Vignal C, Picard H, Leturcq T, Miranda S, Sene T, Gerardin E, Lecler A (2020) Increased diagnostic accuracy of giant cell arteritis using three-dimensional fat-saturated contrast-enhanced vessel-wall magnetic resonance imaging at 3 T. Eur Radiol 30(4):1866-1875. https://doi.org/10. 1007/s00330-019-06536-7

38. Siemonsen S, Brekenfeld C, Holst B, Kaufmann-Buehler AK, Fiehler J, Bley TA (2015) 3T MRI reveals extra- and intracranial involvement in giant cell arteritis. AJNR Am J Neuroradiol 36(1):91-97. https://doi.org/10.3174/ajnr.A4086

39. Kobayashi M (2019) Ischemic stroke due to sarcoidosis: the arterial wall enhancement on magnetic resonance imaging. Neurol Sci 40(9):1967-1970. https://doi.org/10.1007/s10072-019-03862-y

40. Kaido T, Otsuki T, Ogawa M, Takahashi A, Kaneko Y, Yamamoto T, Nakata Y (2012) Medullary ischemia due to vertebral arteritis associated with Behcet syndrome: a case report. Asian Pac J Allergy Immunol 30(3):239-242

41. Sarbu MI, Sarbu N (2020) Fulminant brain atrophy and vasculitis on vessel-wall imaging in neuropsychiatric lupus: case report and literature review. Arch Rheumatol 35(3):443-448. https://doi.org/ 10.46497/ArchRheumatol.2020.7544

42. Takeshita S, Ogata T, Tsugawa J, Tsuboi Y (2020) Isolated cerebral vasculitis in the unilateral middle cerebral artery in a case with SLE. Intern Med 59(24):3225-3227. https://doi.org/10.2169/ internalmedicine.4958-20

43. Padrick MM, Maya MM, Fan Z, Szumski N, Lyden PD, Song SS, Dumitrascu OM (2020) Magnetic resonance vessel wall imaging in central nervous system vasculitides: a case series. Neurologist 25(6):174-177. https://doi.org/10.1097/NRL.0000000000000298

44. Yahyavi-Firouz-Abadi N, Kiczek M, Zeiler SR, Wasserman BA (2021) Imaging features of susac syndrome on high-resolution intracranial vessel wall MRI. Neurol Neuroimmunol Neuroinflamm. https://doi.org/10.1212/NXI.0000000000000994

45. Lersy F, Anheim M, Willaume T, Chammas A, Brisset JC, Cotton F, Kremer S (2021) Cerebral vasculitis of medium-sized vessels as a possible mechanism of brain damage in COVID-19 patients. J Neuroradiol 48(3):141-146. https://doi.org/10.1016/j.neurad. 2020.11.004

46. Lu T, Zou Y, Jiang T, Yang Y, Wu A, Chen H, Kang Z, Lin X, Fang Y, Lu Z (2020) Intracranial artery injury in HIV-negative tuberculous meningitis: a high-resolution vessel wall imaging study. Clin Neuroradiol 30(2):381-388. https://doi.org/10.1007/ s00062-019-00766-4

47. Lopes AJM, Caldas JG, Ferraz F, Teixeira MJ, Figueiredo EG (2019) Vessel wall MRI revealing inflammation on brain aneurysm associated to chronic mucocutaneous candidiasis. Br J Neurosurg 33(5):577-578. https://doi.org/10.1080/02688697.2017. 1384794

48. Askar W, Nadeem I, Dalby J, Hunter P, Kuchinsky G, Wolfe T, Stoner B (2021) The use of intracranial vessel wall magnetic resonance imaging to detect a presumptive syphilitic brain aneurysm. Sex Transm Dis. https://doi.org/10.1097/OLQ.0000000000 001432

49. Bauerle J, Zitzmann A, Egger K, Meckel S, Weiller C, Harloff A (2015) The great imitator-still today! A case of meningovascular syphilis affecting the posterior circulation. J Stroke Cerebrovasc Dis 24(1):e1-3. https://doi.org/10.1016/j.jstrokecerebrovasdis. 2014.07.046

50. Kurian M, Pereira VM, Vargas MI, Fluss J (2015) Stroke-like phenomena revealing multifocal cerebral vasculitis in pediatric lyme neuroborreliosis. J Child Neurol 30(9):1226-1229. https:// doi.org/10.1177/0883073814552104

51. Lebas A, Toulgoat F, Saliou G, Husson B, Tardieu M (2012) Stroke due to lyme neuroborreliosis: changes in vessel wall contrast enhancement. J Neuroimaging 22(2):210-212. https://doi. org/10.1111/j.1552-6569.2010.00550.x

52. Li M, Wu SW, Xu WH (2015) High-resolution MRI of radiationinduced intracranial vasculopathy. Neurology 84(6):631. https:// doi.org/10.1212/WNL.0000000000001223

53. Lou X, Ma N, Ma L, Jiang WJ (2013) Contrast-enhanced 3T highresolution MR imaging in symptomatic atherosclerotic basilar artery stenosis. AJNR Am J Neuroradiol 34(3):513-517. https:// doi.org/10.3174/ajnr.A3241

54. Goldstein ED, Majersik JJ, McNally S (2020) Intracranial high-resolution vessel wall imaging in CADASIL. Neurology 94(23):1040-1041. https://doi.org/10.1212/WNL.0000000000 009588

55. Ryoo S, Cha J, Kim SJ, Choi JW, Ki CS, Kim KH, Jeon P, Kim JS, Hong SC, Bang OY (2014) High-resolution magnetic resonance wall imaging findings of Moyamoya disease. Stroke 45(8):24572460. https://doi.org/10.1161/STROKEAHA.114.004761

56. Kim YJ, Lee DH, Kwon JY, Kang DW, Suh DC, Kim JS, Kwon SU (2013) High resolution MRI difference between moyamoya 
disease and intracranial atherosclerosis. Eur J Neurol 20(9):13111318. https://doi.org/10.1111/ene.12202

57. Kong DZ, Lian YH, Wang LJ, Wang CM, Meng YY, Zhou HW (2019) Central nervous system vasculopathy caused by Fabry disease: a case report. BMC Neurol 19(1):115. https://doi.org/10. 1186/s12883-019-1348-9

58. Schaafsma JD, Hui F, Wisco D, Staugaitis SM, Uchino K, Kouzmitcheva E, Jaigobin C, Hazrati LN, Mikulis DJ, Mandell DM (2017) High-resolution vessel wall MRI: appearance of intravascular lymphoma mimics central nervous system vasculitis. Clin Neuroradiol 27(1):105-108. https://doi.org/10.1007/ s00062-016-0529-9

59. Brinjikji W, Mossa-Basha M, Huston J, Rabinstein AA, Lanzino G, Lehman VT (2017) Intracranial vessel wall imaging for evaluation of steno-occlusive diseases and intracranial aneurysms. Journal of neuroradiology=Journal de neuroradiologie 44(2):123-134. https://doi.org/10.1016/j.neurad.2016.10.003

60. Lindenholz A, Harteveld AA, Zwanenburg JJM, Siero JCW, Hendrikse J (2018) Comparison of 3T intracranial vessel wall MRI sequences. AJNR Am J Neuroradiol 39(6):1112-1120. https://doi. org/10.3174/ajnr.A5629

61. Brinjikji W, Lehman V, Huston J 3rd, Luetmer PH, Lanzino G, Rabinstein AA (2019) Decreased vessel wall enhancement as a biomarker for response to corticosteroids in a patient with CNS vasculitis. J Neurosurg Sci 63(1):100-101. https://doi.org/10. 23736/S0390-5616.16.03723-1

62. Tsivgoulis G, Papadimitropoulos GN, Lachanis S, Palaiodimou L, Zompola C, Antonellou R, Voumvourakis K (2018) High-resolution intracranial vessel wall imaging in monitoring treatment response in primary CNS angiitis. Neurologist 23(6):188-190. https://doi.org/10.1097/NRL.0000000000000198

63. Hauenstein C, Reinhard M, Geiger J, Markl M, Hetzel A, Treszl A, Vaith P, Bley TA (2012) Effects of early corticosteroid treatment on magnetic resonance imaging and ultrasonography findings in giant cell arteritis. Rheumatology 51(11):1999-2003. https://doi.org/10.1093/rheumatology/kes153

64. Kerr GS, Hallahan CW, Giordano J, Leavitt RY, Fauci AS, Rottem M, Hoffman GS (1994) Takayasu arteritis. Ann Intern Med 120(11):919-929. https://doi.org/10.7326/0003-4819-120-11199406010-00004

65. Lee YC, Padera RF, Noss EH, Fossel AH, Bienfang D, Liang MH, Docken WP (2012) Clinical course and management of a consecutive series of patients with "healed temporal arteritis." J Rheumatol 39(2):295-302. https://doi.org/10.3899/jrheum.110317 